\title{
Conversion Analysis of a Planetary Chain-Set Speed Reducer into a Speed Increaser to Be Used in RES
}

\author{
C. Jaliu ${ }^{1}$, D.V. Diaconescu ${ }^{1}$, R. Săulescu ${ }^{1}$ and O. Climescu ${ }^{1}$ \\ ${ }^{1}$ Department of Product Design and Robotics, Transilvania University of Brasov \\ no. 29, Eroilor Boulevard, 500036, Brasov, Romania, \\ Phone/Fax number:+40 268 472496, \\ e-mail: cjaliu@unitbv.ro,dvdiaconescu@unitbv.ro,rsaulescu@unitbv.ro, blackjetster@gmail.com.
}

\begin{abstract}
Most renewable energy systems (RES) require a transmission to modify the input speed into the desired output speed. The solar systems drive trains include a speed reducer, while the wind turbines and hydro units' usually contain a gearbox to increase the speed of the input shaft to the generator.

The paper main objective is analyzing the conversion possibilities of a proposed planetary chain-set from speed reducer into a speed increaser, by inverting the energy flow. The transmission is meant to be used in the RES applications (small wind turbines and hydropower stations).

By inverting the energy flow, the reducer can become speed increaser only if its efficiency is positive. Therefore, the variation of the kinematical ratio $i$ (first as reducer and, then, as increaser) and the variation of the afferent efficiencies are further analyzed comparatively, in the paper. The results interpretation highlight the conditions in which the chain transmission can be used as speed reducer and speed increaser and form a data basis for choosing the proper solution of chain transmission for a certain application (in terms of teeth numbers and efficiency).
\end{abstract}

\section{Key words}

Planetary chain-set transmission, renewable energy systems RES, reduction/multiplication ratio, efficiency.

\section{Introduction}

Most renewable energy systems include a transmission to adapt the speed of the input shaft to the output needs. In the solar systems case, a method for increasing the amount of received solar radiation consists in using tracking systems, which are mechatronic systems that ensure the optimal positioning of the panels with respect to the sun. Thus, many solar tracking systems include a speed reducer aimed to obtain the solar panel low speed motion and, thus, to reduce sometimes over 100 times the actuator motion [2]. Unlike the solar systems, the wind turbines and small hydropower plants need a gearbox to increase the speed of the turbine shaft according to the needs of the electric generator. An increase in speed is needed because the wind turbines rotors and the hydro turbines shafts turn at a much lower speed than is required by most generators. The range in which the input angular speed must be increased is $3-5$ for small hydros $[3,4]$ and $6-30$ for the wind turbines [6].

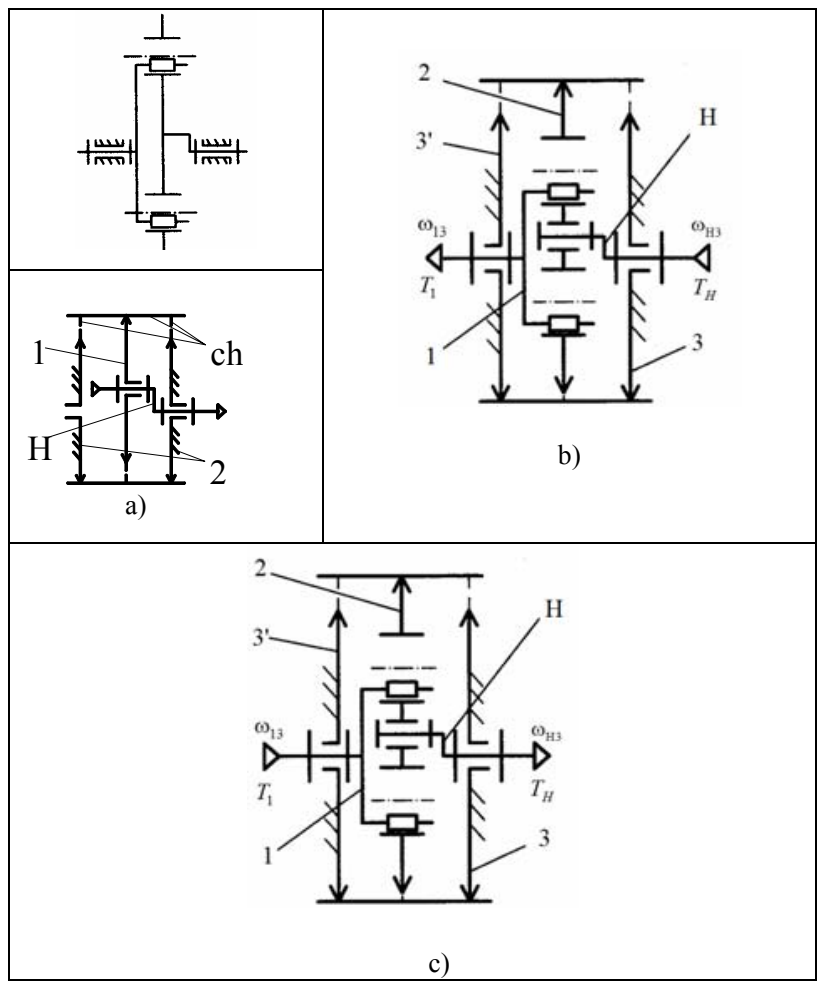

Fig. 1. Schemes of the transmission running cases: a) components (Schmidt coupling, chain transmission), b) speed reducer, b) speed increaser

New solutions of planetary speed increasers for RES were proposed by the authors in the previous papers [4, $5,7,10]$. This paper main objective is to enlarge the base of speed increasers for small wind and hydro stations with innovative planetary chain-set transmissions. The paper is analyzing the conversion possibilities of a proposed planetary chain-set speed reducer $[8,9]$ into a speed increaser, by inverting the energy flow.

The proposed planetary chain speed reducer, illustrated in Fig. 1, a is developed combining a chain transmission and the Schmidt (pin) coupling (see Fig. 1,a), by applying 
a conceptual design algorithm [8,9]; the reducer can be used in the solar panel orientation and in other multifarious domains; in this case, the flow of energy goes in through the carrier $\mathrm{H}$ (see Fig, 1, b) and goes out through the sun gear 1. By inverting the energy flow, the reducer from Fig. 1, a can become speed increaser (see Fig. 1, c) if its efficiency is positive. The variation of the kinematical ratio $i$ (first as reducer and, then, as increaser) and the variation of the afferent efficiencies are further analyzed comparatively. The results interpretation highlight the conditions in which the planetary chain-set transmission can be used as speed reducer and speed increaser and form a data basis for choosing the proper solution of chain transmission for a certain application (in terms of teeth numbers and efficiency). In order to compare the transmission properties in both cases, the same running parameters, such as gears teeth numbers and transmission ratio range were considered.

\section{Comparative Analysis}

The comparative analysis of the two running cases (speed reducer and speed increaser) from Fig. 1, b and c, is systematized in Table 1 and Fig. 2 - 5; in this analysis, the following main parameters are calculated: the internal kinematical ratio $i_{0}(1)$, the internal efficiency $\eta_{0}(2)$; a direct relation between the teeth numbers of the satellite gear 2 and sun gears $3 \equiv 3^{\prime}$ ( 3 ) is imposed to fulfil the transmission requirements related to a smaller overall dimension:

$$
\begin{gathered}
i_{0}=i_{13}^{H}=\frac{\omega_{1 H}}{\omega_{3 H}}=i_{12}^{H} \cdot i_{23}^{H}=(+1)\left(+\frac{z_{3}}{z_{2}}\right) \\
\eta_{0}=\eta_{13}^{H}=\eta_{12}^{H} \cdot \eta_{23}^{H} \\
\Delta z=z_{3}-z_{2} \text { (see Fig. } 1 \text { ) }
\end{gathered}
$$

The transmission reduction/multiplication ratios $i$ and the efficiency $\eta$ are calculated by means of relations (4) and (5) from Tab. 1:

\begin{tabular}{|c|c|}
\hline Speed reducer & Speed increaser \\
\hline Fig. 1,b & Fig. 1,c \\
\hline$i=i_{H 1}^{3}=\frac{\omega_{H 3}}{\omega_{13}}=\frac{\omega_{3 H}}{\omega_{3 H}-\omega_{1 H}}=\frac{1}{1-i_{0}}$ & $i_{1 H}^{3}=\frac{\omega_{13}}{\omega_{H 3}}=\frac{\omega_{1 H}-\omega_{3 H}}{-\omega_{3 H}}=1-i_{0}=1 / i$ \\
\hline$\eta=\eta_{H 1}^{3}=\frac{-\omega_{13} T_{1}}{\omega_{H 3} T_{H}}=\frac{-T_{1} / T_{H}}{\omega_{H 3} / \omega_{13}}=\frac{1-i_{0}}{1-i_{0} \eta_{0}^{w}}$ & $\eta=\eta_{1 H}^{3}=\frac{-\omega_{H 3} T_{H}}{\omega_{13} T_{1}}=\frac{1-i_{0} \eta_{0}^{x}}{1-i_{0}}$ \\
\hline $\begin{array}{r}w=\operatorname{sgn}\left(\omega_{1 H} T_{1}\right)=\operatorname{sgn}\left(\frac{\omega_{1 H} T_{1}}{-\omega_{13} T_{1}}\right)=\operatorname{sgn}\left(\frac{i_{0}}{1-i_{0}}\right) \\
(6)\end{array}$ & $x=-w$ \\
\hline
\end{tabular}

Table 1. The transmission parameters in both running cases: speed reducer and speed increaser

where: $i_{0}$ and $\eta_{0}$ are the internal kinematical ratio and the internal efficiency, respectively (parameters of the associated transmission with fixed axes, which is derived from the planetary transmission by the motion inversion); $i_{x y}^{z}$ is the transmission ratio from element $\mathrm{x}$ to element $\mathrm{y}$, while element $\mathrm{z}$ is considered blocked; $\omega_{x y}$ represents the relative speed between elements $\mathrm{x}$ and $\mathrm{y}$.

\section{Numerical Simulation}

The diagrams from Fig. 2, 3, 4 and 5 present, comparatively, the values of the transmission ratio and efficiency for the speed reducer and speed increaser; in order to present the parameters variation superposed in the same diagram, the values of the transmission ratio are given in module (Fig. 3 and 5) and are multiplied 5 times.

In the comparative numerical simulations, illustrated in Fig. 2 - 5, the following premises are used:

- the internal efficiency of Schmidt coupling is 0.995 ;

- the internal efficiency of the chain-set transmission varies between $\eta_{0}^{\min }=0.86$ and $\eta_{0}^{\max }=0.98$;

- for an easer comparison, the same internal parameters $i_{0}$ and $\eta_{0}$ were considered in the numerical simulations of the two running cases;

- the parameters $z_{2}$ and $\Delta z$ (Fig. 1) have the following values: $z_{2}=24$ (Fig. 2, 3, 4,a), 16 (Fig. 2, 3, 4,b); $\Delta \mathrm{z}=1,2,3, \ldots, 10$;

- the diagrams present two constructive cases: $z_{3}<z_{2}$ (-delta_z, Fig. 2 and 4), and $z_{3}>z_{2}$ (delta_z, Fig. 3 and 5);

The variations from Fig. $2-5$ highlight the fact that, in the same conditions (same values of the parameters $i_{0}, \eta_{0}$, $\mathrm{z}_{2}$ and $\Delta \mathrm{z}$ ), the chain-set reducers have better efficiencies than the chain increasers.
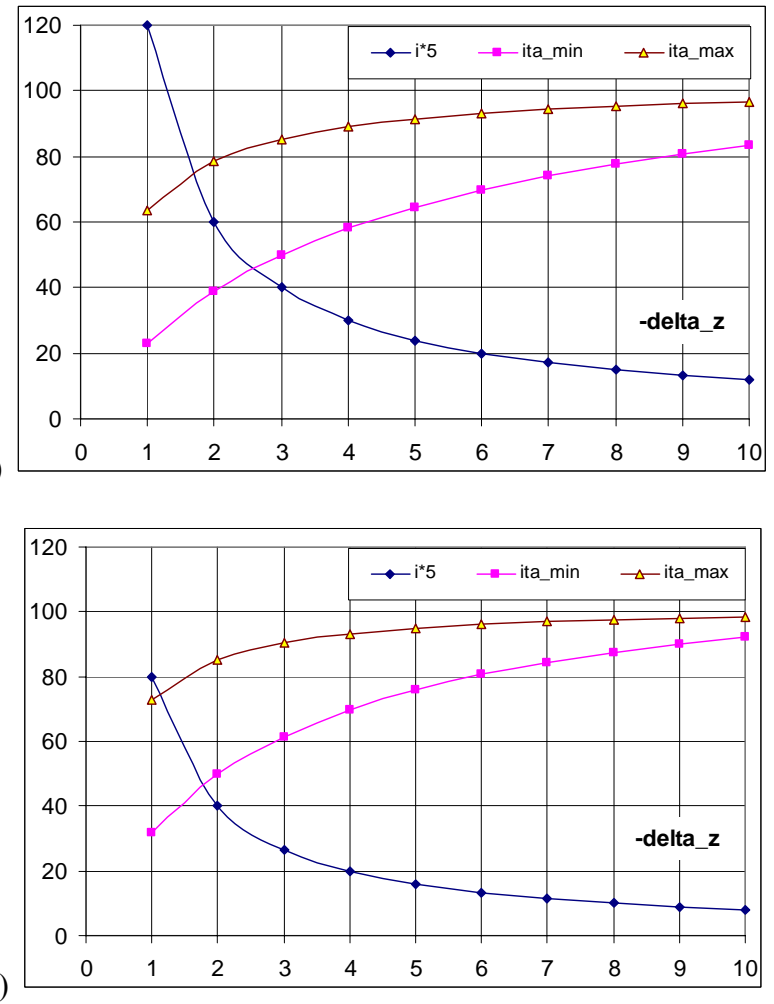

Fig. 2 Simulations for speed reducer in the case $\mathrm{z}_{3}<\mathrm{z}_{2}$ : a) $\left.\mathrm{z}_{2}=24, \mathrm{~b}\right) \mathrm{z}_{2}=16$. 

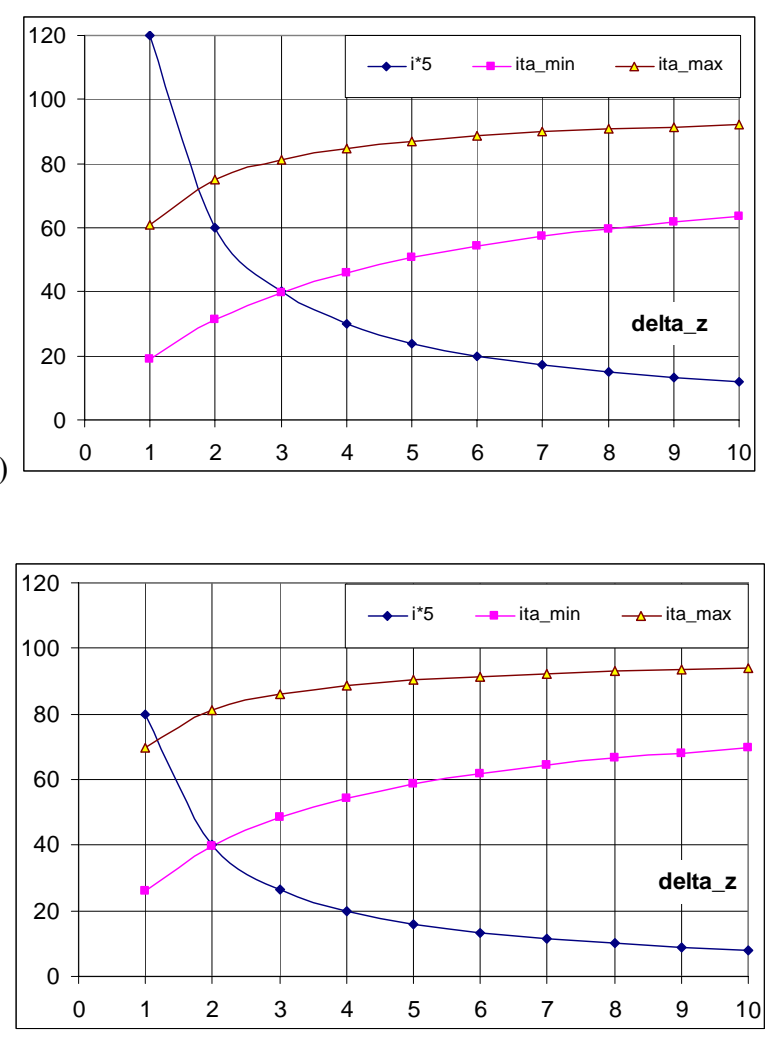

Fig. 3 Simulations for speed reducer in the case $z_{3}>z_{2}$ : a) $\left.\mathrm{z}_{2}=24, \mathrm{~b}\right) \mathrm{z}_{2}=16$.

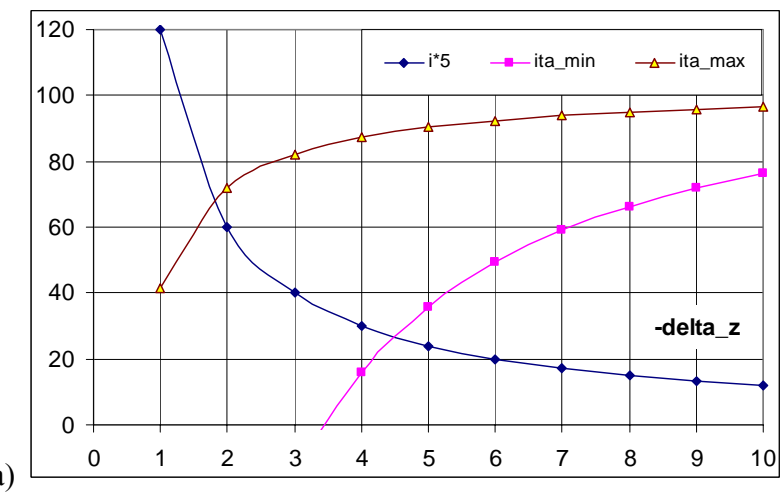

a)

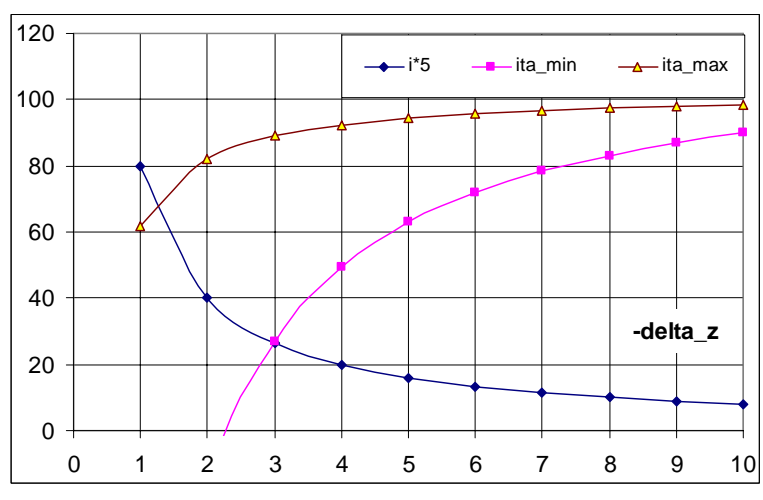

Fig. 4 Simulations for speed increaser in the case $\mathrm{z}_{3}<\mathrm{z}_{2}$ : a) $\left.\mathrm{z}_{2}=24, \mathrm{~b}\right) \mathrm{z}_{2}=16$.
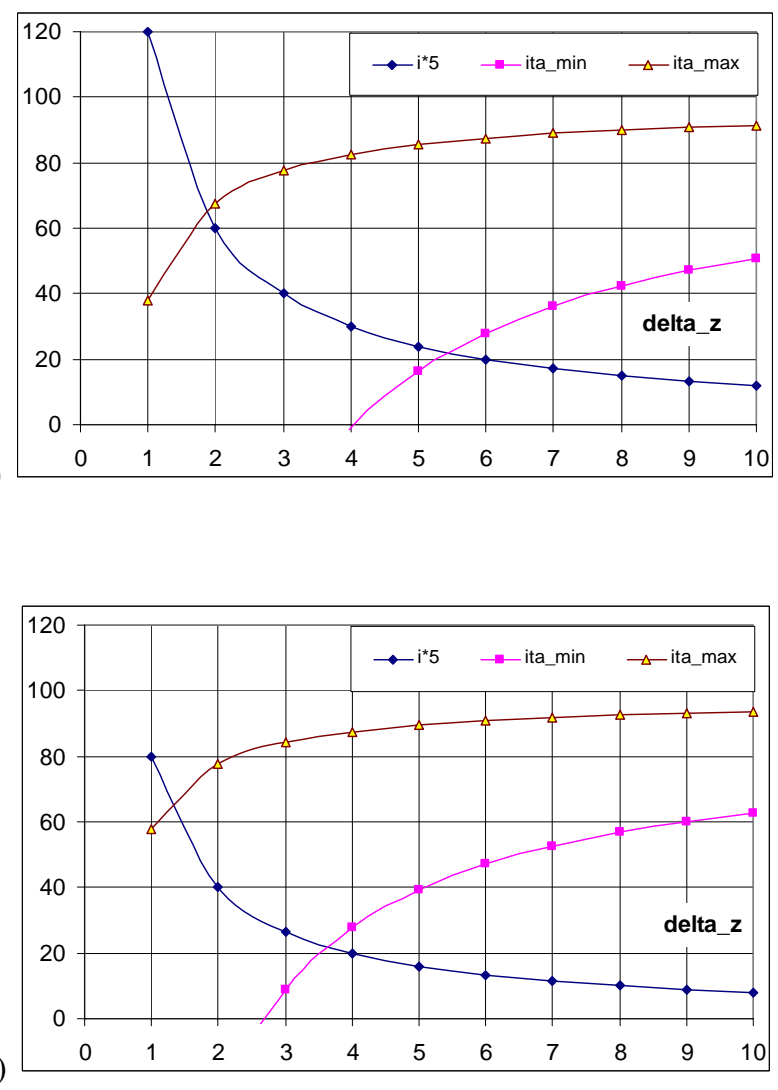

Fig. 5 Simulations for speed increaser in the case $z_{3}>z_{2}:$ a) $\left.\mathrm{z}_{2}=24, \mathrm{~b}\right) \mathrm{z}_{2}=16$.

\section{Remarks and Conclusions}

From the comparative analysis of the simulation results systematized in Fig. 2-5, can be stated the following conclusions:

1) the proposed transmission is recommended to be used mostly in small hydropower plants, due to the higher values of the efficiency for a transmission ratio between 3 and 5;

2) in certain conditions, the transmission can function in two constructive situations: $\mathrm{z}_{3}<\mathrm{z}_{2}$ and $\mathrm{Z}_{3}>\mathrm{z}_{2}$, the first one having higher values of the efficiency;

3 in the same conditions (the same values of parameters $i_{0}, \eta_{0}, z_{2}$ and $\Delta z$ ) the speed reducer has a higher efficiency than the speed increaser;

4) if $z_{2}$ is unchanged and $\Delta z$ increases, $i$ decreases and $\eta$ increases;

5) if $\Delta z$ is unchanged and $z_{2}$ decreases, $i$ decreases and $\eta$ increases;

6) if $z_{2}$ is unchanged and $\Delta z$ unchanged, i unchanged and $\eta$ decreases;

7) if $i$ is unchanged and $z_{2}$ decreases, $\Delta z$ decreases and $\eta$ increases;

8) if $\eta_{0}$ is small, the chain transmission can act as reducer in all considered cases (see Fig. 2 and 3), while it can act as increaser only with the increase both of $z_{2}$ and $\Delta z$ (i.e. $z_{2}=16, \Delta z>3$, Fig. 4 , b and 
5 , b, and, respectively for $\mathrm{z}_{2}=24, \Delta \mathrm{z}>4$, Fig. 4 , a and $5, a)$

9) in the reducer case, the efficiency zone has reduced modifications vs. $\mathrm{z}_{2}$, while in the increaser case, big modifications interfere;

10) a chain transmission which acts as increaser needs a higher technological accuracy than the same transmission that acts as reducer.

\section{Acknowledgement}

The authors will accomplish the design, manufacturing and testing of the speed increaser for stand-alone hydropower stations in the framework of the research project "Innovative mechatronic systems for micro hydros, meant to the efficient exploitation of hydrological potential from off-grid sites", ID_140. The preparation and publishing of this paper would not have been possible without the financial support of this research project.

\section{References}

[1] American Chain Association, "Standard Handbook of Chains: Chains for Power Transmission and Material Handling", $2^{\text {nd }}$ Edition, Dekker Mechanical Engineering, (2005).

[2] Diaconescu, D., "Products Conceptual Design" (Romanian), Transilvania University Publishing House, Brasov (2005).

[3] Harvey, A., "Micro-hydro design manual", TDG Publishing House (2005).

[4] Jaliu, C., Diaconescu, D.V., Neagoe, M. and Săulescu R., 2008, "Dynamic features of speed increasers from mechatronic wind and hydro systems. Part I. Structure. Kinematics.” Proceedings of EUCOMES 08. The Second European Conference on Mechanism Science, Cassino, Italy (2008), Springer Publishing
House, ISBN 987-1-4020-8914-5, pp. 355-363,

[5] Jaliu, C., Diaconescu, D.V., Neagoe, M. and Săulescu R., 2008, "Dynamic features of speed increasers from mechatronic wind and hydro systems. Part II. Dynamic aspects." Proceedings of EUCOMES 08. The Second European Conference on Mechanism Science, Cassino, Italy (2008), Springer Publishing House, ISBN 987-1-4020-8914-5, pp.365-373.

[6] Manwell, J.F., a.o. "Wind Energy Explained", John Wiley \& sons (2005).

[7] Neagoe, M., Diaconescu, D.V., Jaliu, C., Pascale, L., Săulescu, R. and Siscă, S., "On a New Cycloid Planetary Gear used to Fit Mechatronic Systems of RES." OPTIM 2008. Proceedings of the 11th International Conference on Optimization pf Electrical and Electronic Equipment. Vol. II-B. Renewable Energy Conversion and Control. May 22-23.08, Braşov, pp. 439-449, IEEE Catalogue 08EX1996.

[8] Neagoe, M., Diaconescu, D., Jaliu, C. and Săulescu, R., “A conceptual design application based on a generalized algorithm Part I. Generation of solving structural variants". The 19th International DAAAM Symposium. Intelligent Manufacturing \& Automation: Focus on Next Generation of Intelligent Systems and Solutions, Trnava, Slovakia (2008), pp. 0953-0954.

[9] Neagoe, M., Diaconescu, D., Jaliu, C. and Săulescu, R., “A conceptual design application based on a generalized algorithm. Part II. Solving structures selection and evaluation". The 19th International DAAAM Symposium. Intelligent Manufacturing \& Automation: Focus on Next Generation of Intelligent Systems and Solutions., Trnava, Slovakia (2008), pp. 0955-0956.

[10] Jaliu, C., Săulescu, R., Diaconescu, D., Neagoe, M., Conceptual design of a chain speed increaser for small hydropower stations. Proceedings of the ASME 2009 International Design Engineering Technical Conferences \& Computers and Information in Engineering Conference, IDETC/CIE 2009, 30.08 - 2.09, 2009, San Diego, California, USA, CD Proceedings. 